\title{
Enlaces Teóricos e Pedagógicos entre Formação Continuada Docente e Prática Pedagógica com Tecnologias
}

\author{
Adriana Richit \\ Professora, UFFS, Erechim-RS \\ adrianarichit@gmail.com
}

\begin{abstract}
Resumo
$\mathrm{O}$ artigo traz considerações sobre os enlaces teóricos e pedagógicos evidenciados entre o processo de formação continuada de professores da educação básica e o desenvolvimento de práticas pedagógicas pautadas no uso de tecnologias. A análise toma por base os resultados de uma pesquisa de doutorado desenvolvida junto ao Programa de Pós-Graduação em Educação Matemática da UNESP de Rio Claro, SP, Brasil. A referida pesquisa engajou docentes de matemática da rede pública estadual de ensino de um município do interior do Rio Grande do Sul, os quais envolveram-se em uma atividade formativa, na modalidade semipresencial, na qual experimentaram modos distintos de abordar conceitos matemáticos curriculares. Como resultados o estudo evidenciou, entre outras coisas, que a implementação de uma nova prática pelo professor é um processo lento e complexo, perpassado por aspectos de naturezas diversas, tais como as preconcepções do professor sobre o papel das tecnologias na prática pedagógica, o impacto das diretrizes políticas e orientações curriculares nacionais no currículo escolar, as influências dos testes de avaliação da educação, as influências da cultura escolar e o impacto das experiências formativas vivenciadas pelo professor ao longo da carreira. Nesse sentido, enfatiza-se a relevância da formação continuada como uma forma de fomentar e viabilizar mudanças na prática pedagógica.
\end{abstract}

Palavras-chave: Formação continuada docente; Tecnologias Digitais; Educação Matemática.

\section{Links theoretical and pedagogical between teacher's continuing education and pedagogic practice with technology}

\begin{abstract}
The article presents considerations on the links between theoretical and pedagogical highlighted the process of continuing education for teachers of basic education and the development of pedagogical practices based on the use of technologies. The analysis is based on the results of a doctoral research carried out at the Graduate Program in Mathematics Education UNESP, Rio Claro, SP, Brazil. Such research engaged teaching math in public schools teaching an inland city of Rio Grande do Sul, which engaged in a training activity in blended mode, in which experienced different ways of approaching mathematical concepts curriculum. As the study results showed, among other things, that the implementation of a new practice by the teacher is a slow and complex, permeated by aspects of various kinds, such as the teacher's preconceptions about the role of technology in pedagogical practice, the impact policies and guidelines of the national curriculum guidelines in the school curriculum, the influences of education assessment tests, the influences of school culture and the impact of formative experiences experienced by the teacher throughout his career. In this regard, we emphasize the importance of continuing education as a way to encourage and enable change in teaching practice.
\end{abstract}

Key Words: Teacher's Continuing Education; Technology Digital; Mathematic Education. 


\section{Introdução}

Há muito mudanças na prática pedagógica de sala de aula têm sido discutidas e incentivadas no contexto das políticas públicas nacionais e no campo científico da educação, estendendo-se para a educação matemática e áreas adjacentes. A partir desse, emerge um movimento político e pedagógico voltado a promover mudanças na educação mediante a incorporação de tecnologias nos processos educativos. Nesse viés, os Parâmetros Curriculares Nacionais (PCN) e os programas de informatização da educação, tais como o Programa Nacional de Tecnologia Educacional (ProInfo), Programa Um Computador por Aluno (ProUCA), Programa Banda Larga na Escola, entre outros, têm, ao mesmo tempo, fomentado e deflagrado mudanças nas práticas educativas em todos os níveis e redes de ensino.

Contudo, pesquisas, tais como Lima Ferreira (2004), têm mostrado que, em geral, as mudanças relativas à prática de sala de aula e aos modos de se produzir conhecimento não são assimiladas pela escola e seus atores. Segundo Lima Ferreira (2004), a escola encontra-se isolada do contexto social e em descompasso com as mudanças da sociedade. Diz, ainda, que o uso de tecnologias em sala de aula pode modificar as práticas educativas. Para tanto, a escola precisa incorporar as potencialidades dessas a partir da ação e das práticas educativas. Ou seja, em vez de tomar por base "um esquema preestabelecido para aplicar à realidade situacional, procura-se relacionar teoria e prática a partir da implicação dos atores em situação" (LIMA FERREIRA, 2004, p.117).

Por sua vez Mendes (2008), ao investigar indícios de mudanças educacionais mediante a utilização de laptops pelos estudantes, considera que a presença desses recursos no ambiente de sala de aula propiciou mudanças, as quais suscitaram do professor novos modos de gerir a sala de aula e de encaminhar a prática pedagógica.

Analogamente, resultados de pesquisas apontam a formação de professores como um dos principais entraves à implementação de mudanças em educação. Além disso, que os professores têm manifestado resistência em assimilar novas diretrizes e, sobretudo, mudanças na prática. Grosso modo, constata-se que a prática docente de cada professor é influenciada, sobretudo, pelas experiências vivenciadas ao longo das trajetórias escolar e acadêmica (na licenciatura). Nesse viés, a formação continuada tem sido apontada como possibilidade de se promover reflexões sobre as práticas comumente desenvolvidas e as mudanças que se fazem necessárias nos processos educativos na educação básica.

Em face dessas considerações o artigo visa apresentar compreensões acerca dos enlaces teóricos e pedagógicos entre formação continuada docente e prática pedagógica com tecnologias, entendendo-se que as práticas de professores trazem 
subjacente princípios teóricos e metodológicos que, em geral, provém de vivências formativas anteriores, sejam elas escolares, acadêmicas ou profissionais. Para tanto, toma-se por base os resultados de uma pesquisa de doutorado, explicitada em termos metodológicos na próxima seção.

\section{Sobre a pesquisa desenvolvida}

As compreensões apresentadas baseiam-se nos resultados de uma pesquisa de doutorado, conduzida na perspectiva qualitativa segundo a acepção de Denzin e Lincoln (2000), que buscou analisar o processo de apropriação de conhecimentos pedagógico-tecnológicos em matemática de professores. Tal análise considerou a realidade educacional das escolas de educação básica da rede pública estadual de ensino do RS, os fatores (processos) que perpassam essa apropriação, o modo como o movimento das políticas públicas impacta no desenvolvimento profissional do professor e as implicações das ações de formação continuada na cultura e prática cotidiana desses professores.

Guiado por esse objetivo, o estudo constituiu-se de diversas etapas. Principiou com observações da prática de professores de matemática da educação básica e a realização de entrevistas iniciais, prosseguiu no contexto de um processo de formação continuada semipresencial (na modalidade de Curso de Extensão), transitou para o cenário em que os professores promoveram novas práticas usando tecnologias e finalizou com a realização de uma entrevista, quase dois anos após a conclusão do Curso. Ao longo dessas etapas foram utilizados diferentes instrumentos de coleta de dados, tais como questionários, entrevistas, observações em sala de aula, análise de documentos oficiais, gravações em áudio e vídeo, entre outras.

A análise dos dados coletados evidenciou processos diversos que estão imbricados na apropriação de conhecimentos pedagógico-tecnológicos em matemática pelo professor, dentre os quais o modo como esse professor promove novas práticas de sala de aula, práticas essas pautadas no uso de tecnologias e de que maneira a formação docente se reflete nessas práticas. É esse o foco da próxima seção.

\section{Processos inerentes às práticas com tecnologias do professor da educação básica} A respeito das implicações das tecnologias em educação Kenski (2003, p.50) comenta que a apropriação desses recursos pelo professor

pode garantir-lhe segurança para, com conhecimento de causa, sobreporem-se às imposições dos programas e projetos tecnológicos que não tenham 
a necessária qualidade educativa. Criticamente, os professores vão poder aceitá-las ou rejeitá-las em suas práticas docentes, tirando o melhor proveito dessas ferramentas para auxiliar o ensino no momento adequado.

O entendimento presente nas reflexões da autora citada pressupõe olhar as diretrizes e os desdobramentos das ações e políticas de formação continuada de professores, de modo a evidenciar os processos que se fazem presentes na apropriação de novos conhecimentos e práticas. A identificação desses processos pode conduzir à compreensão dos elementos que tomam lugar nas práticas de professores da educação básica, nas quais as tecnologias participam de maneira diferenciada.

Com vistas a acentuar as compreensões acerca dos elementos que perpassam a implementação de práticas com tecnologias, procurou-se compreender a forma como professores promovem práticas com tecnologias. Além disso, procurou-se evidenciar o modo como as experiências formativas perpassam essas práticas.

A análise pautou-se nos registros obtidos no processo de implementação de uma nova prática pedagógica por alguns docentes, sujeitos da pesquisa. Nesse texto são analisadas duas práticas, por meio das quais conceitos matemáticos foram abordados. Tais práticas foram promovidas paralelamente às atividades finais do Curso.

Primeiramente apresenta-se a prática desenvolvida por uma professora, aqui nominada Marina. Essa atividade foi desenvolvida em uma escola pública estadual, denotada Escola C. Marina desenvolveu práticas com três turmas em que ela é docente, duas do $1^{\circ}$ ano do ensino médio e uma do $2^{\circ}$ ano. A análise procedeu-se sobre a prática promovida com o $1^{\circ}$ ano.

Nessa aula, realizada no laboratório de informática da referida escola, Marina abordou o tema "funções polinomiais de $1^{\circ}$ e $2^{\circ}$ graus". Primeiramente retomou diversos conceitos e propriedades, recorrendo a representações gráficas na lousa, e apresentou exemplos de aplicação do conteúdo, visto que a aula foi planejada com o propósito de fechar a unidade de trabalho sobre esse tema, constituindo-se numa revisão do conteúdo.

O texto seguinte é um recorte do plano de trabalho da aula e traz uma síntese das atividades desenvolvidas pelos alunos, para as quais utilizaram o software Graphmatica. 


\section{Excerto 1}

\section{Portfólio Individual: Marina - Atividades Matemáticas}

ESCOLA C

Profa: Marina

1- Em cada função do $1^{\circ}$ grau, determine: f é crescente ou decrescente, coeficiente linear ou valor que toca o eixo $\mathrm{y}$, raiz da função
a) $y=x / 2+4$
b) $\ldots . .$.

Em seguida analisamos na função do $2^{\circ}$ grau, revisando os seguintes conteúdos:

concavidade, zeros ou raízes da função, valores em que a curva toca o eixo x, vértice, valor onde a curva troca de sentido, máximo ou mínimo e seu valor, valor em que a curva toca o eixo y, valor de c.

EXERCÍCIOS

2- Em cada função do $2^{\circ}$ grau, determine: concavidade, raízes da função, vértice, valor que toca o eixo y, máximo ou mínimo, qual?
a) $y=-2 x^{2}+5 x-2$

b) ...

\section{Postada em 25/11/2007}

Analisando o modo como Marina encaminhou a atividade (estudo de funções com o software Graphmática) e a forma como conduz a prática cotidiana, algumas similaridades foram identificadas. Nota-se que ela procede de modo similar no desenvolvimento de sua prática em sala de aula e na implementação de práticas permeadas por tecnologias. Ela utilizou os encaminhamentos didático-pedagógicos da aula clássica, ou seja, realizou explicações iniciais e sistematizou anotações na lousa, explicou as funcionalidades do software e, em seguida, distribuiu uma lista de atividades aos alunos, os quais, organizados em duplas, desenvolveram-nas. Frequentemente a docente auxiliava-os na resolução das questões sugeridas, recorrendo muitas vezes à lousa, onde mostrava a solução trivial, assim como auxiliando os alunos nas dúvidas relativas ao uso do software.

Esses aspectos sinalizam que o conhecimento didático da prática de sala de aula é tomado como ponto de partida na implementação de novas práticas com tecnologias, assim como evidencia o papel da cultura escolar na concretização de mudanças na prática docente.

Por cultura escolar compreende-se, segundo Dayrell (1996, p.137), o ambiente constituído pelas "interações, negociações e compartilhamento de experiências dos sujeitos sócio-culturais que a constituem, sendo que, devido a isso, cada escola possui uma cultura específica que pode até se assemelhar a outras, mas que nunca será a mesma".

Por esse viés, entende-se que a cultura escolar, assim como a própria cultura, constitui-se em um processo dialético a partir das relações e das práticas que perpassam o cotidiano escolar, sendo essas práticas concebidas como ações compartilhadas 
por um determinado grupo cultural. Compõe-se, também, da estrutura escolar e seus aspectos constituintes - projeto político pedagógico, recursos didáticos usados, ações educativas instituídas etc.

Marina disponibilizou no Portfólio do TelEduc ${ }^{1}$ as atividades matemáticas desenvolvidas nessa prática, justificando a escolha do tema, os objetivos desse trabalho e, também, o modo como propôs cada exercício, conforme ilustra o depoimento seguinte.

No ensino médio, na $1^{\mathrm{a}}$ série, elaborei exercícios que fixassem as quatro funções: $1^{\circ}$ grau, $2^{\circ}$ grau, exponencial e logarítmica. Coloquei questões de simples aplicação de conteúdo e outras com exemplos aplicados a outras áreas do conhecimento. Meus objetivos eram de revisão do conteúdo, tendo em vista as recuperações próximas da data aplicada, visualização do que tínhamos estudado no papel, estimular a interpretação gráfica e fixar o conteúdo estudado como parte dos conteúdos para vestibular, objetivo principal do curso. (Marina, Mensagem postada no Portfólio Individual em 25/11/2007).

A docente propôs, também, exercícios envolvendo funções exponenciais e logarítmicas, com ênfase na resolução de problemas, conforme ilustra o excerto seguinte.

\section{Excerto 2}

\section{Portfólio Individual: Marina - Atividades Desenvolvidas com o software Graphmática} ESCOLA C

Profa: Marina

1-Um comerciante gastou $\mathrm{R} \$ 300,00$ na compra de um lote de maçãs e cada maçã será vendida a $\mathrm{R} \$ 2,00$. Assim o lucro com a venda das maçãs será dado pela lei $\mathrm{y}=2 \mathrm{x}-300$.

a) para que não haja lucro nem prejuízo, quantas maçãs precisarão serem vendidas?

b) Se não forem vendidas as maçãs, de quanto será o prejuízo?

c) A partir de qual número de maçãs vendidas o comerciante terá lucro? $2-\ldots$

4-Na função $\mathrm{y}=4^{\mathrm{x}}$, responda:

a) é crescente ou decrescente;

b) toca o eixo y? em que valor?

c) toca o eixo $\mathrm{x}$ ?

5-O número de bactérias de uma cultura, t horas após o início de certo experimento, é dado pela expressão $\mathrm{N}(\mathrm{t})=1200 \cdot 2^{0,4 \mathrm{t}}$. Ou $\mathrm{y}=1200(2)^{(0,4 \mathrm{x})}$. Nessas condições, quanto tempo após o início do experimento a cultura terá 38400 bactérias.

$6-\ldots$

1. Plataforma de Educação a Distância, desenvolvida pelo Núcleo de Informática Aplicada a Educação (NIED) da UNICAMP. 
7-Na função $y=\log _{5} x$, responda:

a) é crescente ou decrescente

b) toca o eixo $x$ ? em que valor? toca o eixo $y$ ?

c) qual o valor de y para $\mathrm{x}=125$ ?

Postada em 25/11/2007

Analisando as atividades mostradas no excerto 2 verifica-se que Marina preocupou-se em contemplar a resolução de problemas. Essa característica do trabalho proposto ressalta o impacto dos Parâmetros Curriculares Nacionais (PCN) nas práticas promovidas pelos professores, visto que a resolução de problemas e o uso de tecnologias fazem parte das tendências do ensino preconizadas nesse documento.

Do mesmo modo, conforme depoimento da docente, nota-se que as tendências verificadas nos testes de avaliação da educação básica, como o Prova Brasil e o Sistema de Avaliação da Educação do Rio Grande do Sul - SAERS, têm suscitado mudanças nas práticas pedagógicas. Segundo ela, a resolução de problemas e a análise de gráficos, tendências essas presentes nesses testes, vêm sendo incorporadas às atividades propostas aos alunos.

Contudo, embora haja preocupação com a adaptação do ensino escolar às diretrizes instituídas pelos PCN, verifica-se que ainda não há uma cultura de uso das tecnologias, conforme afirma Kenski (2007), assim como de resolução de problemas, investigação matemática etc., e, com isso, predominam as abordagens baseadas em livros didáticos, os quais têm norteado e delineado a prática docente escolar e o programa curricular.

A esse respeito Stahl (2008, p.299) considera que o processo de mudanças na escola pressupõe que os professores compreendam que

a entrada da sociedade na era da informação exige habilidades que não têm sido desenvolvidas na escola, e que a capacidade das novas tecnologias de propiciar aquisição de conhecimento individual e independente implica num currículo mais flexível, desafia o currículo tradicional e a filosofia educacional predominante, e depende deles a condução das mudanças necessárias.

Ao conversar com Marina sobre o modo como havia planejado e desenvolvido as atividades matemáticas, procurando saber como ela compreendia o papel da tecnologia no trabalho desenvolvido e na aprendizagem dos alunos, diversos aspectos foram destacados, conforme depoimento a seguir.

Pesquisadora: Como você vê o papel da tecnologia, do software, nessas atividades? De que forma o Graphmática contribuiu na abordagem do tema funções e pode ter favorecido a aprendizagem dos seus alunos? 
Marina: Eu percebi que os alunos ficaram motivados pra fazer as atividades, porque é uma aula diferente. Eles saíram da sala animados pra ir para o laboratório e isso já torna a aula melhor, mais proveitosa pra eles. Assim, no começo eles ficaram perdidos, eles tinham bastante dúvida sobre o software, mas depois eles pegaram o jeito. Eu vejo assim, que o papel do software, no caso o Graphmática, foi uma forma de mostrar pra eles tudo aquilo que a gente viu na sala de aula, mostrar na prática coisas como coeficiente linear, concavidade, pontos de mínimo e máximo. E como eles puderam rever todas essas coisas, né, na tela do computador, eles fixaram melhor esse conteúdo, aprendendo melhor (Entrevista, outubro de 2007).

Para essa professora, o uso de tecnologias na prática docente torna a abordagem diferente e, esse aspecto contribui para motivar os alunos, fazendo com que se interessem pela aula. Assinala, também, que as tecnologias permitem ao aluno aprender os conceitos matemáticos a partir da sua representação gráfica, visto que ele precisa identificá-los nas representações exibidas na tela do computador.

Assim, para essa professora a implementação de uma nova prática caracteriza-se como uma inovação metodológica em termos da prática docente, bem como evidencia o impacto da prática formativa vivida na cultura e prática dessa professora. Marina avalia essa experiência de forma positiva, expressando em diferentes momentos e situações sua satisfação, realização pessoal e profissional, por sentir-se capaz e ousar experimentar uma nova prática, na qual as tecnologias fizeram-se presentes.

A aplicação do software Graphmática em minhas aulas teve inúmeros pontos positivos. Entre eles posso destacar: realização pessoal; respeito; expressões de prazer por parte dos alunos; clareza nas interpretações; demonstrações de entendimento do que tínhamos estudado em aula (até por parte daqueles que em provas escritas não tinham mostrado resultados positivos); interesse; atenção; familiaridade com a informática (é o dia-a-dia deles, o mundo deles); interação professor-aluno, aluno-professor; troca de experiências; investigação além da prevista em sala; interdisciplinaridade; rapidez na troca de informações; as notas da avaliação proposta. (Marina, Mensagem postada no Portfólio Individual em 25/11/2007).

Sobre isso entende-se que o fato do processo formativo implementado ter sido planejado a partir da realidade deles, das suas necessidades, bem como ter sido realizado no contexto da prática (no lócus do trabalho do professor), focando conteúdos específicos da área de conhecimento e curriculares das séries que lecio- 
nam, favoreceu o envolvimento deles nas atividades e a implementação de novas práticas pedagógicas.

Em outras palavras, tal como propõem Santos (2008) e Simião (2006), promover formação docente contextualizada pode ser um caminho de favorecer o desenvolvimento profissional do professor em consonância com a sua realidade, prioridades e interesses e, portanto, pode desencadear mudanças na prática pedagógica.

Por outro lado, o modo como Marina promoveu a prática reflete suas preconcepções sobre o papel das tecnologias no ensino de matemática, pois essas atividades foram desenvolvidas para "fixar" o conteúdo estudado em sala de aula, servindo como uma revisão à prova que seria realizada posteriormente. Esse aspecto sinaliza que mudanças em termos da cultura e prática docente escolar demandam tempo e práticas formativas diferenciadas.

A outra prática analisada foi desenvolvida também na escola $\mathrm{C}$, com uma classe de alunos do $3^{\mathrm{a}}$ ano do ensino médio. A professora responsável pela atividade é aqui chamada Débora. Débora promoveu dinâmicas de aprendizagem usando os softwares MuPAD e Wingeom. Na primeira atividade, com o MuPAD, foram desenvolvidas questões sobre polinômios, tais como valor numérico, soma e diferença de polinômios e representação gráfica em duas e três dimensões de vários tipos de funções.

Já o trabalho desenvolvido com o software Wingeom consistiu no desenvolvimento de um projeto em que foram abordados conteúdos de geometria espacial. Primeiramente, Débora propôs algumas atividades envolvendo sólidos geométricos. Após, desenvolveu uma prática com alunos que estavam em recuperação em matemática. Nesse trabalho, o qual se constituiu na avaliação final da disciplina, os alunos, distribuídos em grupos, elaboraram atividades envolvendo conceitos de geometria espacial. O excerto seguinte expõe uma atividade elaborada por um dos grupos de alunos, que aborda noções espaciais como volume, capacidade volumétrica máxima, razão entre volumes, definição de cone reto, esfera etc.

\title{
Excerto 3
}

\author{
Atividade de Geometria Espacial Elaborada pelo Grupo 6 - \\ Profa. Débora \\ ATIVIDADE DESENVOLVIDA COM O SOFTWARE \\ WINGEOM \\ Num recipiente cônico de raio 3, completamente cheio com \\ água, foi introduzida uma esfera maciça como mostra a figura. \\ a) Qual é o raio da Esfera? \\ $R$ : O raio da esfera se mede de $D$ a F como observa-se na \\ figura \\ (linear $/$ segmento ou face/enter), $d f=2,07900 \mathrm{~cm}$.
}

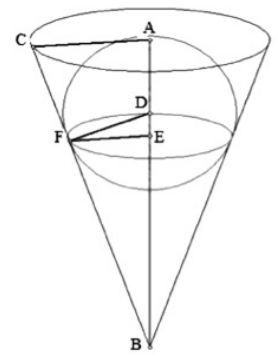


a) Qual o volume de água que permaneceu no cone?

$R$ : $O$ volume do cone é igual a $75,39 \mathrm{~cm}^{3}$.

$O$ volume da esfera é de $37,64 \mathrm{~cm}^{3}$.

Para encontrar o volume de água que permaneceu

no cone (ãac^ $2 * b a / 3-4 / 3 \tilde{a} d f^{\wedge} 3$ ), calculamos o

volume do cone menos o volume da esfera o que resultou em $37,75 \mathrm{~cm}^{3}$.

Alunos da Escola C $-3^{\circ}$ Ano -2007

A maneira como a atividade está apresentada evidencia traços da abordagem convencional de sala de aula mescladas ao uso dos recursos e da linguagem simbólica do Wingeom, indícios esses que sinalizam a coexistência de movimentos de mudança e resistência nos processos educativos e na realização de novas práticas. Dito de outro modo, embora haja iniciativa à implementação de modificações na prática docente, os procedimentos pedagógicos da aula clássica estão impregnados na prática do professor, definindo seu perfil profissional e, portanto, condicionando o processo de desenvolvimento profissional. Esses aspectos corroboram o papel da cultura escolar nas práticas promovidas pelo professor, consonante Dayrell (1996) e Pérez Gómez (2001).

Da mesma forma, sinalizam que o conhecimento do professor sobre modos de conduzir a prática de sala de aula constitui-se numa dinâmica, tal como preconiza Kosik (2002), na qual tomam lugar os conhecimentos e concepções prévias, as condições de trabalho e fatores internos e externos que pressionam o professor. Assim, é importante que as ações formativas valorizem o conhecimento do professor e seus modos de conduzir a prática pedagógica em sala de aula, pois fornecem subsídios à implementação de novas práticas.

Portanto, é a partir das práticas cotidianas que a escola transmite, modifica, produz e reproduz sua própria cultura. Nesse movimento comparece, além da cultura escola, a cultura docente, que é definida por Pérez Gómez (2001, p.164) como “o conjunto das crenças, valores, hábitos e normas dominantes que determinam o que este grupo social considera valioso em seu contexto profissional, assim como os modos politicamente corretos de pensar, sentir, atuar e se relacionar".

Após a atividade Debora foi convidada a refletir sobre a contribuição das atividades à aprendizagem dos estudantes e da relevância do papel da tecnologia na realização dessas atividades.

Pesquisadora: Como você vê a contribuição das atividades elaboradas pelos alunos para a aprendizagem deles? De que forma a tecnologia, o Wingeom contribuiu na abordagem dos conteúdos focados nas atividades de geometria espacial? Débora: Bom, eu acredito que a partir desta metodologia, destas atividades, os alunos puderam experimentar muitas formas de explorar os conteúdos de 
geometria espacial e eles tiveram contato com outras ferramentas, porque em sala de aula a gente fica só no quadro e giz, né. Foi legal porque eles tiveram que criar as atividades e também resolver e por isso eles se envolveram mais, eles pesquisavam e testavam as coisas no Wingeom e.... Eu vejo que eles aprenderam muito com isso tudo. Pra mim, eu vejo assim, que no Wingeom eles puderam ver na prática todos aqueles conteúdos que a gente viu na sala de aula ... (Entrevista, dezembro de 2007).

Para Débora, o papel da tecnologia na abordagem de conteúdos matemáticos diz respeito à "aplicação prática". A tecnologia favorece a interação do estudante com o conteúdo, visto que ele não está apenas limitado a ouvir explicações e resolver operações matemáticas implícitas nas listas de exercícios dos livros didáticos, mas sim, ele é mobilizado a pensar sobre os conteúdos, pesquisar, fazer experimentações matemáticas, testar conjecturas e propor conclusões.

De acordo com a avaliação das docentes a realização dessa atividade significou um avanço, uma inovação na prática pedagógica, pois ousaram propor uma aula diferente e sentiram-se capazes de mudar. Sobre isso Moretti (2007) e Costa (2004) preconizam que à medida que o docente envolve-se na elaboração de novas propostas de trabalho, ele reconstrói seu conhecimento sobre aquele conteúdo, ao tempo que experimenta novas práticas.

Nota-se que para Marina e Débora, o papel das tecnologias no ensino de matemática está relacionado à visualização, e motivação à aprendizagem, pois esses recursos propiciam aulas diferentes, estimulando o envolvimento do estudante com a aula. Esse depoimento explicita a concepção acerca do papel educacional das tecnologias arraigada no âmbito da escola pública, ao mesmo tempo em que reforça a necessidade do professor vivenciar novas e distintas situações de uso das mesmas no ensino de matemática, corroborando as considerações de Bairral (2007) e Kenski (2007). Para esses autores, as ações formativas para uso pedagógico das tecnologias assumem importante papel na qualificação da prática docente e em favor da transformação da escola.

Diante disso, considera-se necessário ampliar as ações de formação continuada docente, para que os possam vivenciar novas formas de uso desses recursos, contemplando os conteúdos da área específica e as necessidades dessas áreas e do contexto escolar específico. É preciso, ainda, que todos os segmentos da escola sejam engajados nesse movimento, uma vez que todos precisam aceitar e apoiar mudanças na escola (DAYRELL, 1996).

Além disso, a estrutura das atividades elaboradas e as reflexões das professoras sobre o trabalho desenvolvido mostram que concepções prévias permearam 
o processo de experimentar uma nova prática. Marina comenta "que o papel do software, no caso o Graphmática, foi uma forma de mostrar pra eles tudo aquilo que a gente viu na sala de aula, mostrar na prática coisas como coeficiente linear, concavidade, pontos de mínimo e máximo".

Em contrapartida, as atividades desenvolvidas por Débora, e alguns aspectos das atividades promovidas por Marina, contemplam a perspectiva assumida nas atividades promovidas no Curso, evidenciando, assim o impacto da experiência vivida na implementação de uma nova prática e na cultura docente no âmbito das escolas envolvidas.

Em síntese, visto que alguns sujeitos da pesquisa usaram as tecnologias na perspectiva das concepções manifestadas inicialmente e outros utilizaram-nas na perspectiva assumida nas atividades do Curso, considera-se que a implementação de novas práticas pelo professor é permeada, entre outras coisas, pelas preconcepções desse profissional acerca do papel das tecnologias no ensino de matemática, ressaltando a dialeticidade do processo de apropriação de novos conhecimentos pelo professor, segundo preconiza Kosik (2002).

Outro aspecto evidenciado na implementação de uma nova prática diz respeito às mudanças no contexto da prática. Sobre isso Débora destaca que o uso de tecnologias na aula

proporciona uma nova forma de pensar, de fazermos descobertas da teoria, colocarmos em prática conceitos teóricos na matemática, é uma pesquisa em movimento, por isso ainda nos assusta, mas devemos tentar (Débora, Portfólio Individual, 08/11/07).

A partir das práticas promovidas, Débora considera que as tecnologias propiciam uma aprendizagem dinâmica, pois estimulam novas formas de pensar, favorecem descobertas da teoria etc. E mesmo que essa iniciativa represente um desafio, o professor precisa ousar.

Por último, analisando o desenvolvimento dessas experiências foi possível perceber o deslocamento do eixo da prática pedagógica, que na aula clássica centra-se na figura do professor e na aula pautada no uso de tecnologias alterna-se continuamente entre professor e aluno. Verifica-se, também, que houve maior interação entre docentes e discentes, que foi permeada por momentos de discussão e reflexão sobre formas de realizar representações gráficas e/ou geométricas, conjecturas sobre relações entre elementos constituintes dessas figuras, bem como dos conceitos matemáticos presentes nas mesmas e os possíveis processos de desenvolvimento de tais atividades.

Assim, baseando-se em Pérez Gómez (1998), considera-se que os processos de mudança identificados mostraram que há uma interdependência entre as mudan- 
ças pessoais, profissionais e organizacionais deflagradas no cotidiano do professor. Com isso, entende-se que as práticas formativas, promovidas no âmbito da escola, precisam valorizar os conhecimentos da prática dos professores, pois esses são ampliados por meio da ressignificação das práticas produzidas e das interlocuções e interações entre os personagens do cenário escolar.

Por fim, embora as concepções prévias dos professores sobre o papel das tecnologias tomaram lugar na implementação de novas práticas, mudanças no âmbito da dinâmica da aula foram percebidas. A partir dessas constatações e das considerações de Kosik (2002), depreende-se que o embate entre as preconcepções dos docentes e a concretização do uso das tecnologias na prática deflagra mudanças no modo como essa nova prática se constitui e nas relações e interlocuções que aí se estabelecem.

\section{Referências}

COSTA, G.L.M. O Professor de Matemática e as Tecnologias de Informação e Comunicação: abrindo caminho para uma nova cultura profissional. $171 \mathrm{f}$. Tese (Doutorado em Educação). Universidade Estadual de Campinas, Campinas, 2004.

BAIRRAL, M.A. Discurso, Interação e Aprendizagem Matemática em Ambientes Virtuais a Distância. Seropédica: Edur, 2007.

DENZIN, N.K.; LINCOLN, Y. S. Introduction: The Discipline and Practice of Qualitative Research. In: DENZIN, N.K.; LINCOLN, Y.S. Handbook of Qualitative Research. $2^{\text {nd }}$ ed. London: Sage. p.01-28, 2000.

DAYRELL, J. (Org.). A escola como espaço sócio-cultural. In: DAYRELL, J. Múltiplos Olhares sobre Educação e Cultura. Belo Horizonte: UFMG, p.136-164, 1996.

MENDES, M. Introdução do LapTop Educacional em Sala de Aula: indícios de mudanças na organização e gestão da aula. 159 f. Dissertação (Mestrado em Educação: Currículo). Pontíficia Universidade Católica de São Paulo, São Paulo, SP, 2008.

KENSKI, V. M. Tecnologias e Ensino Presencial e a Distância: o novo ritmo da informação. Campinas: Papirus, 2007.

KENSKI, V. M. Tecnologias e Ensino Presencial e a Distância. Campinas: Papirus, 2003. 
KOSIK, K. Dialética do Concreto. 7.ed. Tradução de Célia Neves e Alderico Toríbio. Rio de Janeiro: Paz e Terra, 2002.

LIMA FERREIRA, C.A. A formação e a prática do professor de História: enfoque inovador, mudança de atitudes e incorporação das novas tecnologias nas escolas públicas e privadas do estado da Bahia, Brasil. 363 f. Tese (Doutorado em Educação) Universidade Autônoma de Barcelona - Departamento de Pedagogia Aplicada, Barcelona, Espanha, 2004.

MORETTI, V.D. Professores de Matemática em Atividade de Ensino: uma perspectiva histórico-cultural para a formação docente. 297 f. Tese (Doutorado em Educação). Universidade de São Paulo, São Paulo, 2007.

PÉREZ GÓMEZ, A. I. A cultura escolar na sociedade neoliberal. Porto Alegre: ArtMed, 2001.

PÉREZ GÓMEZ, A. A função e formação do professor/a no ensino para a compreensão: diferentes perspectivas. In: SACRISTÁN, J.G.; PÉREZ GÓMEZ, A. Compreender e Transformar o Ensino. Tradução de Ernani da Fonseca Rosa. 4.ed. Porto Alegre: ArtMed, 1998. p.353-379.

SANTOS, T. Formação de Professores: um mapeamento dos grupos e linhas de pesquisa. Revista Pesquisa Qualitativa. São Paulo, ano 3, n.1, p.93-104, mai, 2008.

SIMIÃO, L.F. As Novas Tecnologias e a Formação Continuada de Professores: analisando aprendizagens e processos. 222 f. Tese (Doutorado em Educação) Universidade Federal de São Carlos, São Paulo, 2006.

STAHL, M. A formação de professores para o uso das novas tecnologias de comunicação e informação. In: CANDAU, V.M. (org). Magistério: construção cotidiana. 6.ed. Petrópolis: Vozes, 2008. p.292-317.

Submetido em fevereiro de 2013 Aprovado em agosto de 2013 